\title{
INTERFERÊNCIA DE PLANTAS DANINHAS NA CULTURA DA MANDIOCA EM RESPOSTA À ADUBAÇÃO NPK
}

Rosane Mendonça do Nascimento $^{1^{*}}$, Maurício Robério Silva Soares ${ }^{1}$, Alcebíades Rebouças São José ${ }^{2}$, Denise Soares de Oliveira ${ }^{1}$, John Silva Porto ${ }^{1}$

${ }^{1}$ Programa de Pós-graduação em Agronomia da Universidade Estadual do Sudoeste da Bahia, Vitória da Conquista, Brasil.(ro_brdrmn@hotmail.com)

${ }^{2}$ Departamento de Fitotecnia e Zootecnia/Laboratório de biotecnologia, Universidade

Estadual do Sudoeste da Bahia, Vitória da Conquista, Brasil

Recebido em: 02/10/2017 - Aprovado em: 21/11/2017 - Publicado em: 05/12/2017

DOI: 10.18677/EnciBio_2017B38

\begin{abstract}
RESUMO
O trabalho foi desenvolvido objetivando avaliar a interferência da matocompetição sobre características produtivas e de crescimento da mandioca, submetida ou não à adubação química NPK, em diferentes períodos de controle das plantas daninhas. O experimento foi organizado em dois sistemas de manejo, com e sem adubação NPK, em delineamento de blocos casualizados, com três repetições e seis tratamentos mantidos livres de plantas daninhas. Aos 18 meses após o plantio, foi realizada a avaliação da produtividade de farinha e amido, área foliar total, índice de área foliar, teor de clorofila altura e diâmetro da mandioca. Os dados obtidos foram submetidos à análise de variância com nível de $5 \%$ de significância. Quando verificada diferença significativa procedeu-se à análise de regressão, com auxílio do software para cálculos estatísticos Sisvar versão 5.6. Os melhores resultados de produtividade de farinha, produtividade de amido, altura e teor de clorofila das plantas de mandioca foram obtidos no período em que houve a realização da capina até o final do ciclo da cultura (540 DAP). A adubação química aumentou a produtividade de farinha, a produtividade de amido e a altura das plantas. Não houveram diferenças significativas na interação período $x$ adubação para nenhuma variável avaliada.
\end{abstract}

PALAVRAS-CHAVE: Manihot esculenta Crantz, Matocompetição, Produtividade

\section{INTERFERENCE OF DYNEA PLANTS IN CANDLE CULTURE IN RESPONSE TO NPK FERTILIZATION}

\footnotetext{
ABSTRACT

The objective of this study was to evaluate the interference of matocompetition on productive and growth characteristics of cassava, submitted or not to NPK chemical fertilization, in different periods of weed control. The experiment was organized in two management systems, with and without NPK fertilization, in a randomized block design, with three replications and six treatments kept free of weeds. At 18 months after planting, the evaluation of flour and starch productivity, total leaf area, leaf area index, chlorophyll content, and cassava diameter were evaluated. The data were submitted to analysis of variance with a level of $5 \%$ of significance. When a significant difference was verified, the regression analysis was performed using the ENCICLOPÉDIA BIOSFERA, Centro Científico Conhecer - Goiânia, v.14 n.26; p.409 2017
} 
software for Sisvar version 5.6 statistical calculations. The best results of flour productivity, starch yield, height and chlorophyll content of cassava plants were obtained during the period of weeding until the end of the crop cycle (540 DAP). The chemical fertilization increased the flour yield, the starch yield and the height of the plants. There were no significant differences in the period $x$ fertilization interaction for any evaluated variable.

KEYWORDS: Manihot esculenta Crantz, Matocompetition, Productivity

\section{INTRODUÇÃO}

A mandioca exerce importância fundamental na agricultura familiar, como também na segurança alimentar e nutricional de milhões de pessoas, é a terceira maior fonte de alimento nos trópicos, após o arroz e o milho (FAOSTAT, 2012). Faz parte da dieta da população brasileira, principalmente das pessoas de classes de renda mais baixa (CONAB, 2016). A parte mais importante da planta são as raízes tuberosas, ricas em amido, e utilizadas na alimentação humana e animal ou como matéria prima para diversas indústrias (PERESSIN, 2011).

As regiões que apresentaram as maiores produções de raízes tuberosas em 2015 foram: a região Norte (7,6 milhões de toneladas), seguida das regiões Sul (5,88 milhões de toneladas), Nordeste (5,30 milhões de toneladas), Sudeste $(2,48$ milhões de toneladas) e Centro-Oeste (1,53 milhões de toneladas) (IBGE, 2016). $O$ cultivo da mandioca, no Brasil, é feito dentro de diferentes níveis tecnológicos, sendo cultivada em: fundo de quintal, onde normalmente são cultivadas variedades de baixa toxicidade, utilizadas na culinária principalmente na forma cozida; cultivo de mandioca de subsistência, comumente visualizado na região Norte e Nordeste, geralmente, a produção é industrializada em unidades artesanais e transformada principalmente em farinha de mesa e polvilhos; cultivo em escala comercial, comumente visualizado na região Centro-Sul, caracterizando-se pelo alto conteúdo tecnológico e uso de insumos agrícolas; e a mandioca cultivada embaixo do pivô central, visualizado em regiões de irrigação, principalmente no Nordeste (PERESSIN, 2011).

Esta cultura apresenta crescimento inicial lento e pequena capacidade de sombreamento, características que lhe proporcionam baixa competitividade com 0 mato e elevam o custo de produção. Dentre os danos ocasionados pelas plantas invasoras desta euforbiácea pode-se destacar: redução na produtividade da cultura, aumento no custo de produção, dificuldade na colheita, redução qualitativa do produto colhido e do tempo de comercialização do mesmo (PERESSIN, 2011).

Estudos sobre período de controle das plantas daninhas e as principais infestantes desta tuberosa são necessários nas principais regiões produtoras, pois estes fatores variam com os diferentes locais de cultivo (SILVA et al., 2012). Desta forma, este trabalho objetivou avaliar os efeitos da ausência da matocompetição, em diferentes períodos, na cultura da mandioca, com e sem a adubação NPK, sobre características produtivas e de crescimento desta cultura.

\section{MATERIAL E MÉTODOS}

O experimento foi realizado de janeiro de 2013 a julho de 2014, na área experimental da Universidade Estadual do Sudoeste da Bahia, Campus de Vitória da Conquista-BA (14ํㄱ'S' 4048'W e altitude de $941 \mathrm{~m}$ ). O clima, conforme a classificação de Köppen, é do tipo Tropical de Altitude (Cwa), com precipitação 
média anual de $741 \mathrm{~mm}$. Os dados agrometeorológicos registrados durante a condução do experimento estão apresentados na figura 1.

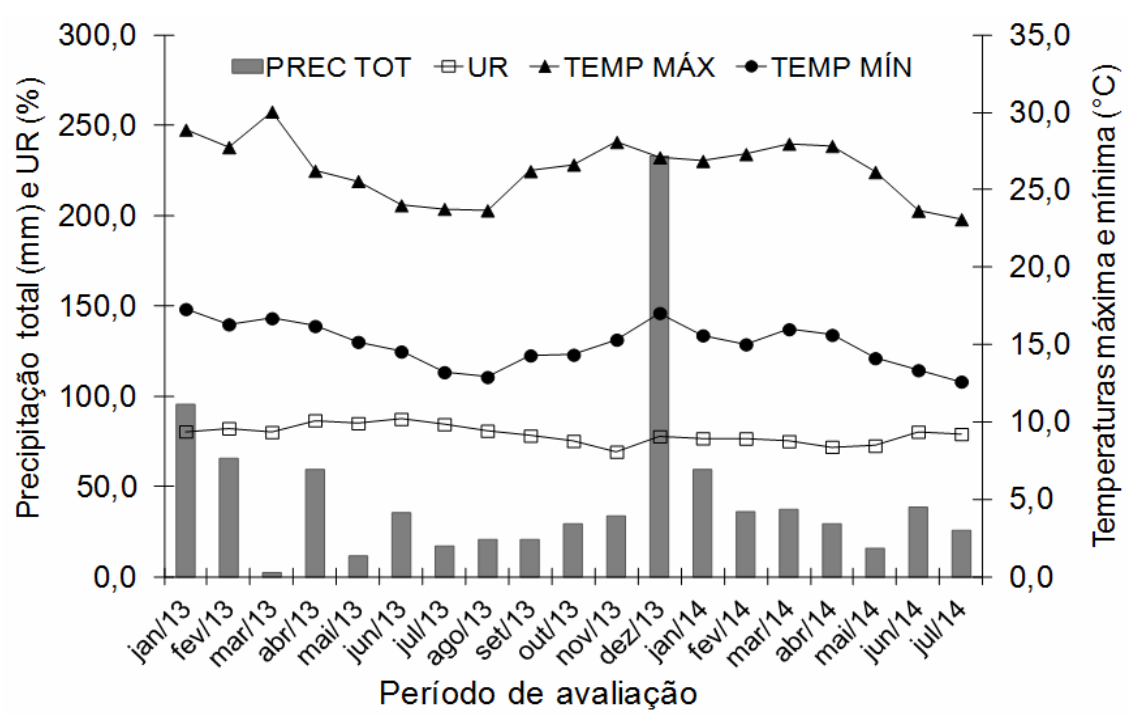

FIGURA 1 - Médias mensais de precipitação ( $\mathrm{mm}$ ), umidade relativa do ar (\%) e temperatura máxima e mínima $\left({ }^{\circ} \mathrm{C}\right)$, em Vitória da Conquista - BA, de janeiro de 2013 a julho de 2014.

Fonte: Instituto Nacional de Meteorologia - INMET, /Vitória da Conquista, BA, (2014).

O plantio foi efetuado manualmente em janeiro de 2013, utilizando-se manivas da variedade industrial Caitité, com 2 a $3 \mathrm{~cm}$ de diâmetro, $20 \mathrm{~cm}$ de comprimento e aproximadamente cinco a sete gemas. O espaçamento adotado foi de $1,0 \mathrm{~m}$ entre fileiras e 0,60 m entre plantas. Cada parcela foi constituída por quatro linhas de 8,4 $\mathrm{m}$ de comprimento e 4,0 $\mathrm{m}$ de largura, totalizando $33,6 \mathrm{~m}^{2}$. A área útil da parcela foi representada por duas linhas centrais, com área de $14,4 \mathrm{~m}^{2}$.

O solo foi preparado de forma convencional, com aração, gradagem e sulcamento. Com base na análise do solo e na recomendação para a cultura, para os tratamentos submetidos à adubação, utilizou-se $40 \mathrm{~kg} \mathrm{ha}^{-1}$ de $\mathrm{P}_{2} \mathrm{O}_{5}$ (na forma de superfosfato simples), aplicados diretamente no sulco de plantio, e $70 \mathrm{~kg} \mathrm{ha}^{-1}$ de $\mathrm{N}$ (ureia) e $30 \mathrm{~kg} \mathrm{ha}^{-1}$ de $\mathrm{K}_{2} \mathrm{O}$ (cloreto de potássio) em cobertura, 60 dias após 0 plantio. No segundo ano da cultura, foram utilizados $60 \mathrm{Kg} \mathrm{ha}^{-1}$ de $\mathrm{N}$ (ureia) e $60 \mathrm{Kg}$ ha $^{-1}$ de $\mathrm{K}_{2} \mathrm{O}$ (cloreto de potássio), aplicados em cobertura no início do período chuvoso (dezembro/2013). Para os tratamentos sem adubação, considerou-se a fertilidade natural do solo.

Os tratamentos foram compostos por diferentes períodos de controle, realizado por meio de capina manual (a cada 15 dias), mantendo-se a cultura livre da interferência das plantas daninhas após o plantio, conforme o Quadro 1, avaliados em parcelas com e sem adubação. 
QUADRO 1 - Descrição dos períodos da mandioca mantida livre de plantas daninhas.

\begin{tabular}{|c|c|}
\hline $\begin{array}{l}\text { Período de } \\
\text { convivência }\end{array}$ & Descrição \\
\hline LPD ${ }^{1 /}$ até 35 DAP $\stackrel{2}{1}$ & Livre de plantas daninhas até 35 dias após o plantio \\
\hline LPD até 70 DAP & Livre de plantas daninhas até 70 dias após o plantio \\
\hline LPD até 105 DAP & Livre de plantas daninhas até 105 dias após o plantio \\
\hline LPD até 140 DAP & Livre de plantas daninhas até 140 dias após o plantio \\
\hline LPD até 175 DAP & Livre de plantas daninhas até 175 dias após o plantio \\
\hline LPD até 540 DAP & Livre de plantas daninhas até o final do ciclo \\
\hline
\end{tabular}

Aos 18 meses após o plantio avaliou-se: a produtividade de farinha ( $\left.\mathrm{t} \mathrm{ha}^{-1}\right)$, obtida pelo produto entre a porcentagem de farinha e a produtividade de raízes tuberosas; produtividade de amido ( $\mathrm{t} \mathrm{ha}^{-1}$ ), calculada pelo produto entre a porcentagem de amido e a produtividade de raízes tuberosas; área foliar total (AFT), utilizando-se o equipamento Area Meter, modelo LI-3100, fabricado pela LI-COR, USA e o índice de área foliar (IAF), obtido a partir da relação entre a área foliar total e a área do solo disponível para a planta (1,0 $\mathrm{m} \times 0,6 \mathrm{~m})$; Teor de clorofila (unidade SPAD), as determinações foram realizadas em 4 folhas da porção mediana da copa, com clorofilômetro marca Minolta, modelo SPAD/502, em cinco plantas por parcela; altura de plantas $(\mathrm{cm})$, obtida a partir do nível do solo até a extremidade mais alta; diâmetro do caule $(\mathrm{cm})$, medido com paquímetro a10 cm do nível do solo.

O delineamento adotado foi o de blocos casualizados, em esquema fatorial $6 \mathrm{x}$ 2 , sendo seis períodos de ausência da competição com plantas daninhas, avaliados com e sem adubação, em três repetições. Os dados obtidos foram submetidos à análise de variância com nível de $5 \%$ de significância. Quando verificada diferença significativa procedeu-se à análise de regressão, com auxílio do software para cálculos estatísticos Sisvar versão 5.6 (FERREIRA, 2010).

\section{RESULTADOS E DISCUSSÃO}

Houve efeito significativo em relação aos diferentes períodos livres da competição com as plantas daninhas e da adubação NPK para as variáveis: produtividade de farinha (PF), produtividade de amido (PA) e altura de plantas (ALT). Houve efeito dos períodos sobre a variável clorofila. Porém, para nenhuma variável foi observada diferença significativa na interação período x adubação (Tabela 1).

TABELA 1 - Resumo da análise de variância e coeficiente de variação para Produtividade de Farinha (PF), Produtividade de Amido (PA), Área Foliar Total (AFT), Índice de Área Foliar (IAF), Clorofila, Altura (ALT) e Diâmetro (DIA) de plantas mandioca.

\begin{tabular}{|c|c|c|c|c|c|c|c|c|}
\hline \multirow{2}{*}{ FV } & \multirow{2}{*}{ GL } & \multicolumn{7}{|c|}{ QUADRADOS MÉDIOS } \\
\hline & & PF & PA & AFT & IAF & Clorofila & ALT & DIA \\
\hline Período(P) & 5 & $18,05^{*}$ & $21,78^{*}$ & 164,99 & 458,36 & $52,11^{*}$ & $2413,99^{*}$ & 1,31 \\
\hline Adubacão(A) & 1 & 15,91 * & $17,36^{*}$ & 46,17 & 128,29 & 0,17 & $4286,76^{*}$ & 0,25 \\
\hline$P \times A$ & 5 & 0,42 & 0,63 & 52,10 & 144,75 & 14,76 & 248,87 & 0,89 \\
\hline Bloco & 2 & 2,53 & 3,58 & 49,39 & 137,25 & 28,86 & $5310,37^{*}$ & 2,77 \\
\hline Resíduo & 22 & 1,02 & 1,19 & 87,84 & 244,01 & 11,52 & 337,29 & 0,95 \\
\hline CV (\%) & & 26,09 & 25,66 & 135,05 & 135,07 & 7,80 & 14,16 & 48,38 \\
\hline
\end{tabular}

${ }^{*}$ Significativo pelo teste $\mathrm{F}$, a $5 \%$ de probabilidade. 
A adubação da mandioca proporcionou aumento de $29,30 \%$ na $P F, 28,29 \%$ na PA e de 15,52\% na ALT (Tabela 2), indicando que a melhora da fertilidade do solo promove efeitos diretos no rendimento da mandioca.

Cardoso Júnior et al. (2005), ao estudarem o efeito da adubação nitrogenada $(0,50,100,200,300$ e $400 \mathrm{~kg}$ ha-1 de N) sobre parâmetros agronômicos da mandioca, verificaram que houve aumento na produtividade de raízes em função da elevação das doses de nitrogênio, alcançando 22,1 t ha-1 na dose de $400 \mathrm{~kg}$ de N, representando um incremento de $20 \%$, comparado ao cultivo sem adubação.

Alves Filho et al. (2015), avaliando a produtividade de mandioca sob o efeito da aplicação de diferentes doses de NPK, verificaram que houve aumento linear da produtividade de raízes em função da adubação mineral NPK. A mandioca se desenvolve e produz relativamente bem em solos de baixa fertilidade, no entanto apresenta respostas significativas ao uso de adubos, com aumentos expressivos na produtividade (FIALHO; VIEIRA, 2011).

TABELA 2 - Produtividade de farinha (PF), produtividade de amido (PPA) e altura (ALT) em plantas de mandioca, em função da adubação.

\begin{tabular}{lll}
\hline \multirow{2}{*}{ Característica } & \multicolumn{2}{c}{ Adubação } \\
\cline { 2 - 3 } & Sem & Com \\
\hline $\mathrm{PF}\left(\mathrm{t} \mathrm{ha}^{-1}\right)$ & $3,21 \mathrm{~b}$ & $4,54 \mathrm{a}$ \\
\hline $\mathrm{PAT}\left(\mathrm{t} \mathrm{ha}{ }^{-1}\right)$ & $3,65 \mathrm{~b}$ & $5,09 \mathrm{a}$ \\
\hline Mé $(\mathrm{cm})$ & $118,79 \mathrm{~b}$ & $140,61 \mathrm{a}$ \\
\hline
\end{tabular}

Médias seguidas por uma mesma letra, na linha, não diferem entre si pelo teste $\mathrm{F} \mathrm{a}$ $5 \%$ de probabilidade.

Pela análise de regressão dos dados constatou-se que o modelo polinomial cúbico foi aquele mais adequado para estimar a produtividade de farinha em função dos períodos livre das plantas daninhas, com e sem adubação. As maiores produtividades de farinha foram observadas quando houve a realização da capina até o final do ciclo da cultura (540 DAP) para o cultivo adubado (7,33 t ha-1) e sem adubação (6,07 t ha-1), com incremento de 17,19 t ha-1 no cultivo adubado, no mesmo período (Figura 2).

Em ambos os cultivos, com e sem adubação, verificou-se que houve acréscimo na produtividade de farinha nos períodos que essa tuberosa foi mantida livre das plantas invasoras por mais tempo. No entanto, é importante salientar que não é recomendável deixar o mandiocal livre de plantas daninhas por todo o ciclo da cultura, haja vista que com a manutenção do solo totalmente livre das plantas invasoras, há aumento da erosão e também maior custo de produção. De acordo Peressin (2011), o controle de plantas daninhas nesta cultura é responsável por aproximadamente $40 \%$ do custo de produção. 


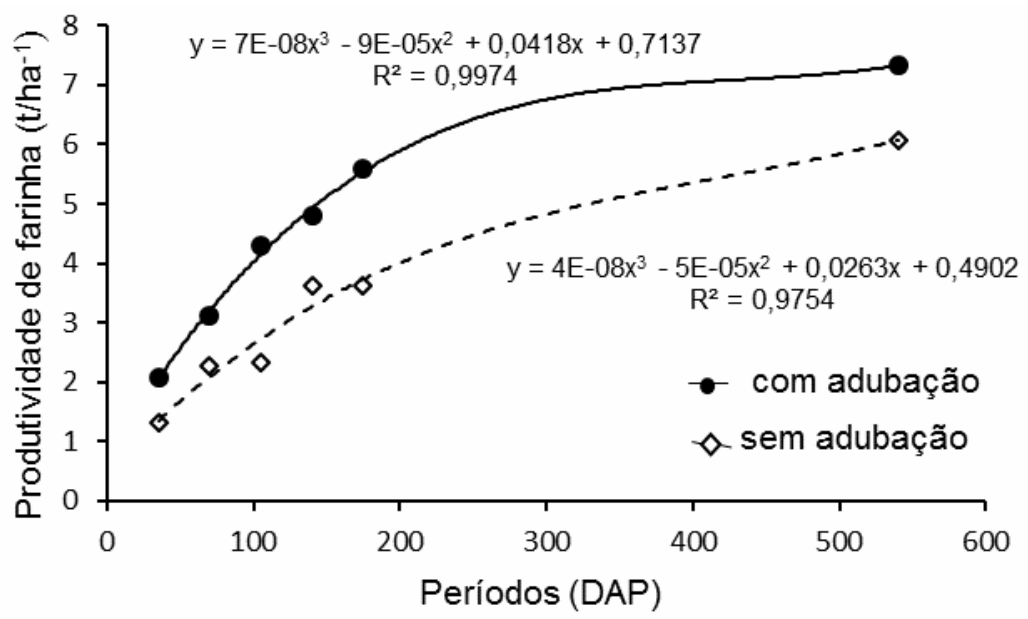

FIGURA 2 - Produtividade de farinha de mandioca, com e sem adubação NPK, em função dos períodos livre de plantas daninhas.

Com pouco tempo depois da brotação da mandioca, pode existir convivência pacífica entre plantas daninhas e a cultura (SILVA et al. 2012). Em estudos realizados por Fontes et al. (2014a) os autores verificaram que a cultivar BRS Purus deve crescer sem a presença de plantas daninhas entre 32 e 125 DAP. Enquanto que a Aipim-manteiga, para evitar a interferência de plantas invasoras e redução de produtividade de raízes, deve ser cultivada livre destas plantas entre 17 e 104 DAP (FONTES et al., 2014b). A manutenção da mandioca livre da competição das plantas daninhas apenas nos primeiros 35,70 e 105 DAP da cultura pode ter contribuído para os menores valores do rendimento de farinha nestes períodos, de 1,32 t ha-1, 2,28 tha-1 e 2,33 t ha-1, respectivamente, no cultivo sem adubação e de 2,08 tha-1, 3,13 tha-1 e 4,3 tha-1, respectivamente, no cultivo com adubação.

Em sistemas de produção de raízes para a indústria, a produtividade de farinha e de amido é essencial para o produtor, pois, através destas características, é possível prever a qualidade do produto e definir os preços para a comercialização (OLIVEIRA et al., 2010).

A produtividade de amido, estimada pela equação de regressão, variou de 2,33 t ha-1 (35 DAP) à 8,00 tha-1 (540 DAP), no cultivo adubado, havendo um acréscimo de $70,88 \%$ desta característica no período que a mandioca foi mantida sem a presença das plantas invasoras durante todo o ciclo, quando comparada ao ser mantida livre destas plantas somente até os 35 DAP. No cultivo sem adubação, a produtividade de amido variou de 1,33 tha-1 (35 DAP) à 6,67 t ha-1 (540 DAP), com incremento de $80,06 \%$ aos 540 DAP em relação aos 35 DAP (Figura 3). A convivência das plantas invasoras com a mandioca por todo o primeiro ciclo vegetativo pode levar à perda na produção da ordem de até $98 \%$ sobre o peso das raízes (PERESSIN, 2011). 


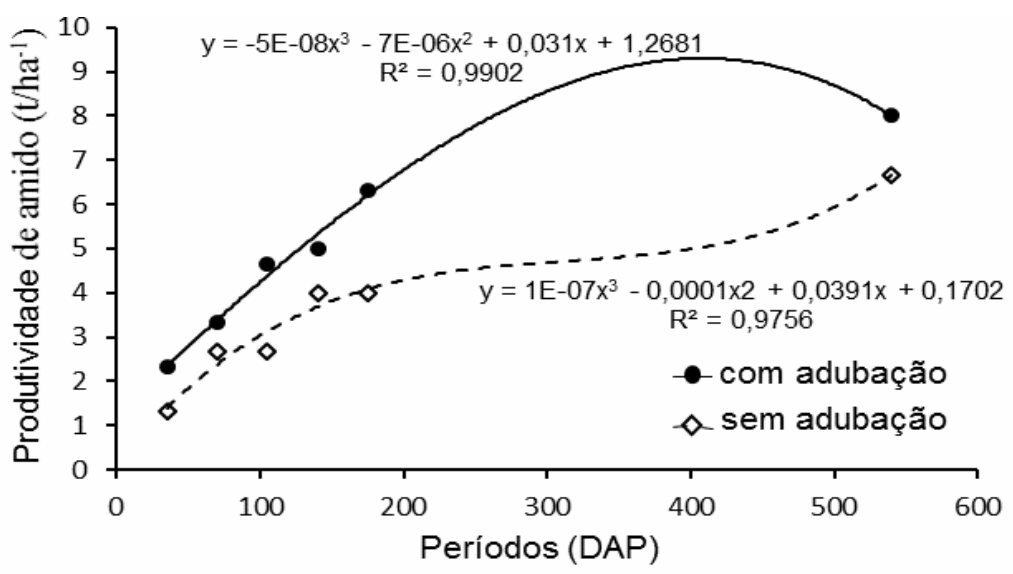

FIGURA 3 - Produtividade de amido de mandioca, com e sem adubação NPK, em função dos períodos livre de plantas daninhas.

A concorrência das plantas invasoras com esta euforbiácea nos primeiros 60 dias reduz pela metade a produção de raízes; após este período, pelo crescimento da cultura acontece o sombreamento, reduzindo, assim, a capacidade vegetativa das plantas invasoras (RODRIGUES FILHO, 2001). A manutenção da mandioca livre de plantas daninhas apenas nos primeiros 35 DAP pode ter contribuído para a menor produtividade de amido neste período.

Quando a colheita da mandioca se estende por dois ciclos vegetativos (18-24 meses), é comum que a mesma entre em repouso fisiológico. Essa fase caracterizase pela queda das folhas e diminuição da atividade metabólica da planta, e a duração decorre, principalmente, dos fatores ambientais. No segundo ciclo que inicia-se a infestação de plantas invasoras (PERESSIN, 2011). Com o aumento do sombreamento da mandioca, a altura da planta se eleva, sem acréscimo no acúmulo de biomassa caulinar e com diminuição do índice de área foliar (CRUZ; PELACANI, 1993).

Desta forma, a cultura deve ser mantida livre da presença da comunidade infestante, de modo que as plantas invasoras que germinarem depois do segundo ciclo não mais promovam interferência e prejudiquem a produtividade da espécie cultivada. No presente estudo, nesta fase a cultura foi mantida livre da matocompetição o que colaborou para o aumento crescente da produtividade de amido.

$\mathrm{Na}$ análise de regressão, observou-se o efeito cúbico dos períodos em que a cultura foi mantida livre das plantas daninhas sobre a altura das plantas. A maior altura de plantas, no cultivo adubado e sem adubação, ocorreu no período que a mandioca foi mantida livre da competição das plantas invasoras por todo o ciclo, com valores de $174,11 \mathrm{~cm}$ e $158,89 \mathrm{~cm}$, respectivamente. Enquanto que as menores alturas de plantas, no cultivo adubado e sem adubação, foram observadas quando a mandioca foi mantida livre das plantas invasoras até $175 \mathrm{DAP}(123,67 \mathrm{~cm})$ e até 70 DAP $(94,83 \mathrm{~cm})$, respectivamente, com incremento de $23,32 \%$ no cultivo adubado (175 DAP) em comparação ao sem adubação (70 DAP) (Figura 4).

Essa variação da altura de plantas, nos diferentes períodos avaliados, em ambos os cultivos, pode ter sido influenciada, pelos fatores ambientais e pelos componentes genotípicos da variedade (VIDIGAL FILHO et al, 2000), além da adubação e das plantas invasoras. As plantas invasoras alteram o desenvolvimento 
dessa tuberosa, e reduz o tamanho, o peso e o número de raízes (SILVA et al., 2012).

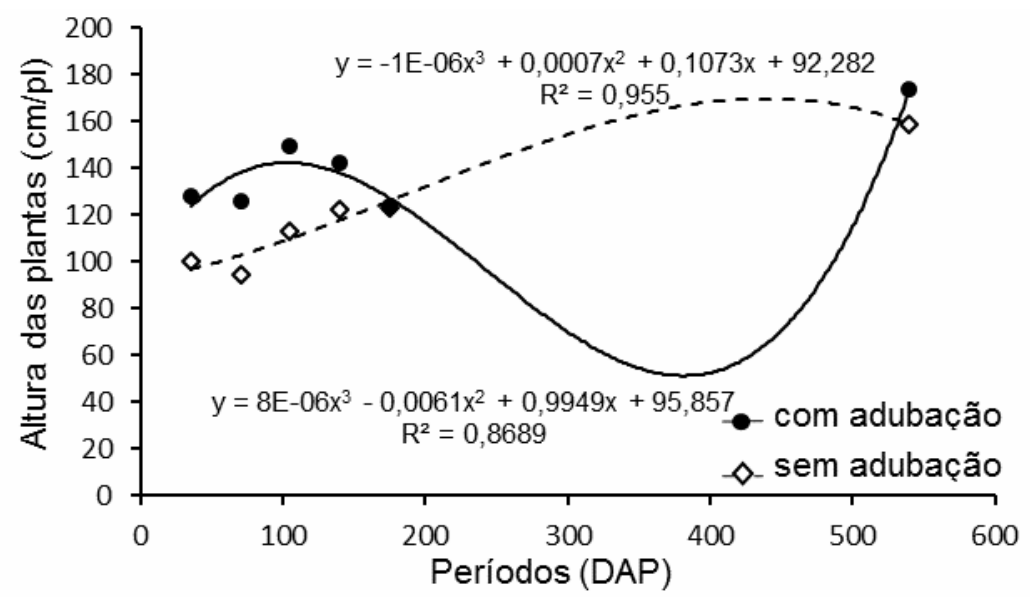

FIGURA 4 - Altura das plantas de mandioca, com e sem adubação NPK, em função dos períodos livre de plantas daninhas.

Rós (2013), avaliando o efeito de diferentes doses de potássio aplicadas em cobertura no crescimento da mandioca, observou efeito linear das doses de potássio sobre a altura das plantas, ocorrendo aumento do porte das plantas com 0 incremento das doses de potássio aplicadas no solo. Segundo o autor, tal fato indica que as plantas têm a produção aérea de matéria verde ampliada à medida que há maiores quantidades de potássio disponível no solo.

O comportamento, em relação à altura, é um fator importante, tanto na competição com plantas infestantes quanto na escolha de cultivares para consorciação com culturas distintas e definição de espaçamento adequado. Quanto ao teor de clorofila, observou-se que não houve diferença para a adubação, demonstrando que a aplicação de fertilizantes na cultura não exerce influência sobre os períodos de competição (Tabela 1).

$\mathrm{Na}$ Figura 5, observa-se o efeito cúbico dos períodos em que a cultura foi mantida livre das plantas daninhas sobre o teor de clorofila. Essa característica, apresentou valor máximo de clorofila (48,77unidade SPAD) no período que a mandioca foi mantida livre da competição destas plantas até os 540 DAP, o menor valor do teor de clorofila $(39,81$ unidade SPAD) foi observado aos 35 DAP.

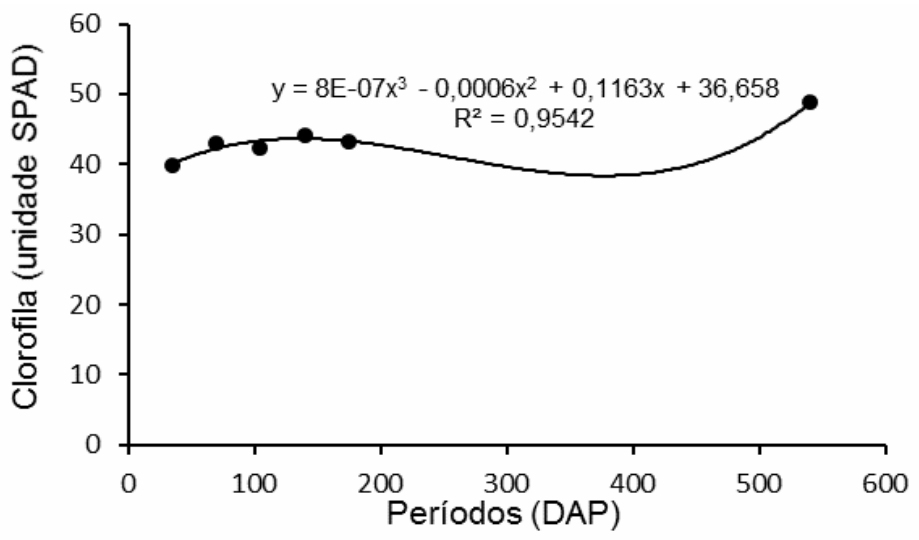

FIGURA 5 - Teor de clorofila de plantas de mandioca, em função dos períodos livre de plantas daninhas, em cultivo com e sem adubação. 
Segundo Peterson et al. (1993), existem fatores que podem afetar leituras dos clorofilômetros como variedades, estádio de crescimento, condições ambientais (temperatura, estresse hídrico, luz, etc.), deficiência nutricional, entre outros. Os menores valores do teor de clorofila foram observados quando a mandioca foi mantida livre de plantas daninhas até os 35 DAP, 70 DAP e 105 DAP, tal fato ocorreu, em função da concorrência das plantas invasoras com a cultura por água, luz, nutrientes, espaço e $\mathrm{CO}_{2}$.

\section{CONCLUSÃO}

Houve diferença entre os períodos livres da competição com as plantas daninhas para as variáveis produtividade de farinha, produtividade de amido, altura e teor de clorofila das plantas de mandioca. Para todas estas características, os melhores resultados foram obtidos no período em que houve a realização da capina até o final do ciclo da cultura (540 DAP).

A adubação química aumentou a produtividade de farinha, a produtividade de amido e a altura das plantas de mandioca. Não houveram diferenças significativas na interação período x adubação para nenhuma variável avaliada.

\section{REFERÊNCIAS}

ALVES FILHO, P. P. C.; GALVÃO, J. R.; NEVES, L. B.; COSTA, I. R. Resposta da cultivar de mandioca roxinha à adubação NPK. Revista Raízes e Amidos Tropicais, v. 11, n.1, p.1-7, 2015. Disponível em: <http://dx.doi.org/10.17766/1808981X.2015v11n1p1-7>. doi: 10.17766/1808-981X.2015v11n1p1-7

CARDOSO JUNIOR, N. S.; VIANA, A. E. S.; MATSUMOTO, S. N.; SEDIYAMA, T.; CARVALHO, F. M. de. Efeito do nitrogênio em características agronômicas da mandioca. Bragantia, v. 64, n.4, p.651-659, 2005. Disponível em: <http://dx.doi.org/10.1590/S0006-87052005000400015>. doi: 10.1590/S000687052005000400015

COMPANHIA NACIONAL DE ABASTECIMENTO - CONAB (2016). Disponível em:<http://www.conab.gov.br/OlalaCMS/uploads/arquivos/16_06_07_11_00_43_conj untura_mensal_mandioca_maio_2016.pdf>. Acesso em: 20 de novembro de 2016 .

CRUZ, J. L.; PELACANI, R. Fisiologia da mandioca. (1993) - In: Curso Nacional De Mandioca, 8, Cruz das Almas. Anais... Cruz das Almas: Embrapa/CNPMF, 1993. $38 p$.

FERREIRA, D. F. (2010) - SISVAR, Versão 5.3 (Build 86) DEX/UFLA.

FIALHO, J. F., VIEIRA, E. A. (2011) - MANEJO DO SOLO NO CULTIVO DE MANDIOCA. IN: FIALHO J F, VIEIRA E A (Eds.). Mandioca no Cerrado: orientações técnicas. Planaltina: EMBRAPA Cerrados. Cap. 3. 2011. 204p.

FONTES, J. R. A.; OlIVEIRA, I. J.; PEDROZO, C. A.; ROCHA, R. N. C.; MORAIS, R. R.; MUNIZ, A. W. Períodos de Interferência de Plantas Daninhas na Cultura 
da Macaxeira, Variedade Aipim-Manteiga, em Terra Firme do Amazonas. Embrapa Amazônia Ocidental: Circular técnica, 46. p. 8., $2014 a$.

FONTES, J. R. A; PEDROZO, C. A.; MORAIS, R. R.; OLIVEIRA, I. J.; ROCHA, R. N. C. Períodos de Interferência de Plantas Daninhas na Cultura da Mandioca, Variedade BRS Purus, em Terra Firme de Rio Preto da Eva, Amazonas. Embrapa Amazônia Ocidental: Circular técnica, 47. p. 8 p., 2014b.

FAOSTAT. Food and Agriculture Organization of the United Nations, 2012. Production, crops. Disponível em: <http://faostat.fao.org/site/339/ default.aspx>. Acesso em: 19 de novembro de 2016.

IBGE - Instituto Brasileiro de Geografia e Estatística, 2016. Disponível em: <http://www.sidra.ibge.gov.br/bda>. Acesso em: 20 de setembro de 2016.

INMET - Instituto Nacional De Meteorologia. Vitória da Conquista, BA, 2014.

OLIVEIRA, S. P.; VIANA, A. E. S.; MATSUMOTO, S. N.; CARDOSO JÚNIOR, N. S.; SEDIYAMA, T.; SÃO JOSÉ, A. R. Efeito da poda e de épocas de colheita sobre características agronômicas da mandioca. Acta scientiarum agronomy, vol. 32, n.1, p. 99-108, 2010. Disponível em: <http://www.scielo.br/scielo.php?script=sci_arttext\&pid=S1807-

$86212010000100015>$.

PERESSIN, V. A. Manejo integrado de plantas daninhas na cultura da mandioca. Campinas: Instituto Agronômico, 54 p., 2011.

PETERSON, T. A.; BLACKMER, T. M.; FRANCIS, D. D.; SCHEPERS, J. S. G931171 Using a chlorophyll meter to improve $\mathbf{N}$ management, 1993. (Historical materials from University of Nebraska-Lincoln Extension, Paper 1353). Disponível em:

$<$ http://digitalcommons.unl.edu/cgi/viewcontent.cgi?article=2349\&context=extensionh ist>. Acesso em: 13 de dezembro de 2016.

RODRIGUES, FILHO. A. A. Cultura da mandioca, 2001. Disponível em: $<$ http://emater.mg.gov.br/doc\%5Csite\%5Cserevicoseprodutos\%5Clivraria\%5CCultur as\%5CCultura\%20da\%20Mandioca.pdf>. Acesso em: 15 de novembro de 2016.

RÓS, A. B. Produtividade de raízes de mandioca em função de doses de potássio. Revista Raízes e Amidos Tropicais, v. 9, n.1, p. 25-32, 2013. Disponível em: <http://dx.doi.org/10.17766/1808-981X.2013v9n1p25-32>. doi: 10.17766/1808981X.2013v9n1p25-32

SILVA, D. V.; SANTOS, J. B.; FERREIRA, E. A.; SILVA, A. A.; FRANÇA, A. C, SEDIYAMA, T. Manejo de plantas daninhas na cultura da mandioca. Planta Daninha, v. 30, n.4, p. 901-910, 2012. Disponível em: <http://dx.doi.org/10.1590/S0100-83582012000400025>. doi: 10.1590/S010083582012000400025 
VIDIGAL FILHO, P. S.; SCAPIM, C. A.; VIDIGAL, M. C. G; MAIA, R. R.; SAGRILO, E. SIMON, G. A.; LIMA, R. S. Avaliação de cultivares de mandioca na região noroeste do Paraná. Bragantia, v. 59, n.1, p.69-75, 2000. Disponível em: <http://dx.doi.org/10.1590/S0006-87052000000100011>. doi: 10.1590/S000687052000000100011 